\title{
Polyelectrolyte Nanocomplex Formation Combined with Electrostatic Self- Assembly Enables the Co-Delivery of Synergistic Antimicrobials to Treat Bacterial Biofilms
}

\author{
Joel A. Finbloom ${ }^{1 *}$, Preethi Raghavan ${ }^{1}$, Bhushan N. Kharbikar ${ }^{1}$, Michelle A. Yu*, Tejal A. Desai ${ }^{1 *}$ \\ ${ }^{1}$ Department of Bioengineering and Therapeutic Sciences. University of California, San Francisco. San \\ Francisco, CA, USA. \\ ${ }^{2}$ Division of Pulmonary and Critical Care Medicine. University of California, San Francisco. San Francisco, \\ CA, USA
}

*Address correspondence to: Joel.Finbloom@ucsf.edu, Michelle.Yu2@ucsf.edu, Tejal.Desai@ucsf.edu

\begin{abstract}
New approaches are needed to treat bacterial biofilm infections, particularly those of Pseudomonas aeruginosa (PA). PA biofilms have high rates of antimicrobial resistance and are commonly found in chronic wound and cystic fibrosis lung infections. The use of combination therapeutics that act synergistically is a promising treatment strategy; however, the delivery of multiple therapeutics at relevant dosages is challenging in the clinic. We therefore developed a new nanoscale drug carrier by combining approaches from both polyelectrolyte nanocomplex (NC) formation and layer-by-layer electrostatic self-assembly. This strategy led to NC drug carriers functionalized with both tobramycin antibiotics and antimicrobial silver nanoparticles with high loading efficiencies. AgTob-NCs displayed synergistic enhancements in antimicrobial activity against planktonic and biofilm PA cultures, with positively charged NCs demonstrating complete biofilm eradication. Overall, this approach shows promise in the co-delivery of diverse classes of antimicrobials to overcome antimicrobial resistance and treat bacterial biofilm infections.
\end{abstract}

Keywords: drug delivery; nanomaterial; biointerface; nanocomplex; cystic fibrosis; antibiotic resistance; bacteria; antimicrobial; biofilm; pseudomonas aeruginosa; tobramycin; silver nanoparticle; polyelectrolyte; layer-by-layer; chitosan

\section{Introduction}

Antimicrobial resistance (AMR) is a global health crisis recognized by the CDC and the WHO as a dire threat to human health. Increasing rates of AMR bacterial infections are outcompeting the development of new antibiotics, and deaths from AMR infections are estimated to increase to over 10,000,000 annual deaths by $2050 .{ }^{1} \mathrm{~A}$ major mechanism of antimicrobial resistance in 
bacterial infections is the development of bacterial biofilms, where bacteria encase themselves within heterogeneous biological hydrogels of extracellular DNA, polysaccharides, and protein filaments. ${ }^{2}$ Biofilm formation directly increases bacterial virulence and leads to AMR mechanisms such as limited antibiotic penetration and increased expression of efflux pumps. ${ }^{2-5}$ Bacterial biofilms are estimated to occur in up to $80 \%$ of human infections and can be up to 1000 times more resistant to antibiotics when compared to planktonic bacteria. ${ }^{2}$ Biofilm infections are particularly prevalent within chronic wounds such as diabetic skin ulcers, as well as in lung infections of cystic fibrosis (CF) patients. In the lungs of CF patients, the viscous mucus layer caused by ineffective mucus clearance by epithelial cells poses an additional challenging barrier to effective bacterial treatment. ${ }^{6-8} \mathrm{CF}$ patients are thus chronically colonized by bacterial biofilms, particularly those of Pseudomonas aeruginosa (PA) bacteria, which once established are nearly impossible to eradicate..$^{7,9-11}$ Chronic colonization by Pseudomonas greatly impacts CF patients' morbidity and mortality to such extents that continuous month-long courses of inhaled tobramycin and inhaled aztreonam antibiotics are often used to suppress pathologic Pseudomonas strains from developing even when the patient is well. Upon developing an exacerbation, CF patients undergo additional parenteral antibiotics for 2 weeks, which leaves them particularly vulnerable to developing colonization with AMR bacteria.

The co-delivery of synergistic antimicrobial drugs could improve the treatment of AMR bacterial biofilm infections. ${ }^{12,13}$ These drug combinations can function in parallel to target orthogonal mechanisms and prevent the evolution of resistance pathways. Alternatively, combination therapeutics can work together to enhance a singular pathway, such as by facilitating increased uptake of an antibiotic for enhanced efficacy.,11-15 One particularly promising combination of antimicrobial therapeutics is tobramycin and silver nanoparticles (AgNPs). Tobramycin (Tob) is an aminoglycoside antibiotic that is the backbone of most antibiotic therapies used in CF exacerbations due to PA. Several studies have demonstrated that tobramycin and AgNPs act synergistically to overcome resistance and treat PA biofilms. ${ }^{16-19}$ While the exact mechanism of action has not yet been elucidated, it is hypothesized that AgNPs inhibit biofilm formation, increase membrane permeability for enhanced Tob uptake, and generate reactive oxygen species for direct bactericidal activities. Despite its potential, one major challenge to antimicrobial codelivery is maintaining local therapeutic concentrations of both drugs at the same site of infection, particularly if the site is difficult to reach. This results in immense burdens for patients, who are frequently exposed to prolonged courses of antibiotics at potent doses, which increases patients' risk for developing adverse reactions and AMR. ${ }^{6}$ For example, chronic osteomyelitis requires a duration of 2-6 weeks of parenteral antibiotics followed by 4-8 additional weeks of oral antibiotics and even then, the infections often cannot be eradicated. ${ }^{20}$ Therefore, new approaches are needed to enable therapeutic co-delivery, improve antimicrobial efficacies, and overcome resistant bacterial biofilm infections. ${ }^{6,21}$

Nanoparticle-based strategies to antimicrobial delivery have seen early preclinical success in sustained drug release and effective bacterial homing. ${ }^{22-30}$ Polymeric particles are widely used as nanoscale drug carriers, as they can be fabricated from biocompatible polymers, loaded with bioactive cargo, and delivered via inhalation. ${ }^{31-34}$ Additionally, polymeric particles have tunable properties such as size, shape, surface charge, and polymer composition, which can influence particle biodistribution, half-life, and interactions with biological barriers such as mucus and bacterial biofilm hydrogels. ${ }^{8,15,35,36}$ Polyelectrolyte nanocomplexes (NCs) are an emerging class of polymeric nanoparticle drug carrier, and are formed through electrostatic interactions between oppositely charged polymers. ${ }^{37,38}$ These NC drug carriers offer physicochemical tunability 
dependent on the polymer ratios, chemical structures, pKa's, and molecular weights. ${ }^{37} \mathrm{NCs}$ have further advantages in their ease of fabrication without specialized equipment, and in their high loading efficiencies of therapeutic cargos, especially for drugs of high charge densities, ${ }^{38-40}$ which often have low encapsulation efficiencies using other polymeric systems. ${ }^{41}$ However, to our knowledge, no examples of NCs have been reported for the co-delivery of antimicrobials, as NC formulations can be challenging to implement for the co-loading of diverse classes of cargo onto a single drug carrier.

To enable the co-delivery of tobramycin and AgNP antimicrobials to treat PA biofilms, we developed a new nanoscale drug carrier fabrication platform that combines approaches from polyelectrolyte nanocomplexation and layerby-layer (LbL) electrostatic self-assembly. This new NC-LbL strategy led to the formation of NCs co-loaded with Tob and AgNPs (Figure 1a). These AgTob-NCs were fabricated from commercially available materials without the use of any specialized equipment or techniques. Additionally, AgTob-NCs offer tunability in particle size and surface charge to engineer the drug carrier biointerface and enhance antimicrobial activity. AgTob-NCs had high degrees of loading for both Tob $(>75 \%)$ and AgNPs (>95\%) and facilitated the co-delivery of Tob and AgNP antimicrobials to eradicate PA biofilms that were resistant to either treatment alone. This approach could see widespread use in enabling the co-delivery of diverse classes of antimicrobials to overcome recalcitrant biofilms such as those present in cystic fibrosis lung infections.

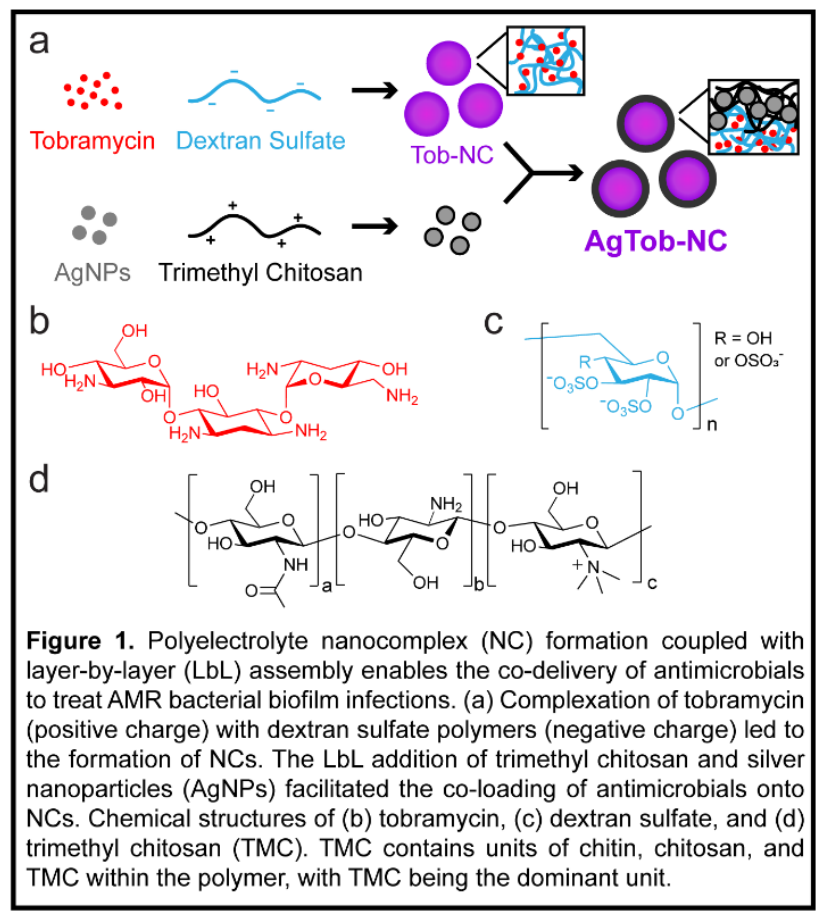

\section{Results and Discussion}

\subsection{Tobramycin Nanocomplex Fabrication and Characterization}

To fabricate nanocomplexes (NCs) co-loaded with tobramycin and silver nanoparticles, NCs were first optimized to encapsulate tobramycin alone, followed by electrostatic layer-by-layer selfassembly with AgNPs (Figure 1a). Tobramycin is an aminoglycoside antibiotic with five potential sites for amine protonation (Figure 1b) and is therefore well-suited for electrostatic incorporation into polyelectrolyte NCs. Dextran sulfate (DS) was chosen as the complementary negatively charged polymer to form Tob-NCs, as its polysaccharide structure and dense negative charge (Figure 1c) make it ideal for complexation with positively charged tobramycin. Tobramycin and dextran sulfate were co-incubated together to form nanocomplexes, which were characterized for particle size and surface charge by dynamic light scattering and zeta potential measurements, respectively (Figure 2a). Tob encapsulation efficiencies were determined by fluorescent $o_{-}$ phthalaldehyde detection assays ${ }^{41}$ of particle suspension supernatants after centrifugation. 
NC formation conditions were optimized for $\mathrm{pH}$ and buffer type, with optimal conditions observed using $50 \mathrm{mM}$ sodium acetate buffer at $\mathrm{pH}$ 4. This $\mathrm{pH}$ allowed for increased protonation of tobramycin amines while maintaining DS negative charge. Tob and DS co-incubation at $\mathrm{pH} 4$ demonstrated increased particle formation when compared to $\mathrm{pH} 6$, wherein no Tob encapsulation or particle formation was observed. Using these optimized conditions, we observed Tob:DS ratio-dependent trends in particle size, surface charge, and encapsulation efficiencies (Figure 2d). A mass ratio of 1:1 Tob:DS led to microparticles of positive charge that were highly polydisperse and had low Tob encapsulation efficiencies (ee\%) of 39\%. As the ratio of Tob:DS increased to $1: 2$, a significant increase in ee $\%$ was observed at $86 \%$, however the particles were of $\sim 1.4 \mu \mathrm{m}$ in diameter, likely too large to penetrate efficiently through bacterial biofilm hydrogels. ${ }^{8,42}$ At Tob:DS ratios of $1: 3$ and 1:4, 250-300 nm particles began to form, with encapsulation efficiencies at 58\% (1:3) and 57\% (1:4). Thus, Tob-NC 1c, corresponding to a Tob:DS ratio of 1:3 was chosen for subsequent AgNP loading and antimicrobial studies.

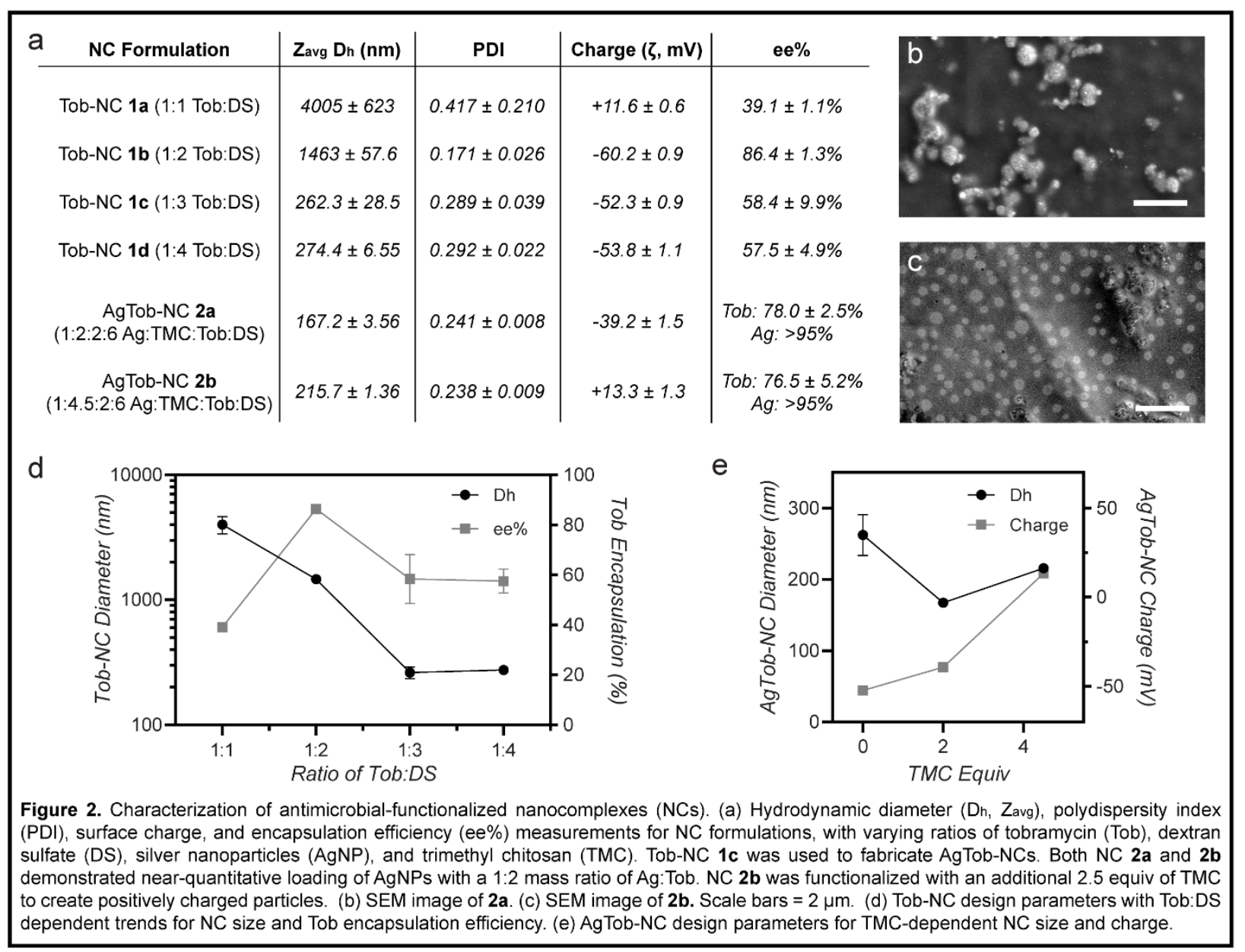

\subsection{AgTob-NC Fabrication and Characterization}

Tob-NCs $\mathbf{1 b}-\mathbf{1 d}$ displayed strong negative charges (Figure 2a), due to the mass ratios of $<1$ Tob:DS within the particles. As AgNPs also have a negatively charged surface owing to their 
citrate coatings, we employed a layer-by-layer ( $\mathrm{LbL}$ ) self-assembly approach to co-functionalize NCs with both Tob and AgNPs. LbL approaches have been used extensively in the field of drug delivery and nanoparticle functionalization, although predominantly with thin films and non-NC formulated polymeric particles. ${ }^{43-46}$ Commercially available $10 \mathrm{~nm}$ AgNPs were chosen for LbL functionalization of Tob-NCs, as we hypothesized that this size would allow for formation of a thin layer on the particle surfaces and have been previously shown to have improved antimicrobial activity when compared to AgNPs of larger size. ${ }^{16}$ Trimethyl chitosan (TMC) was chosen as the positively charged polyelectrolyte to facilitate LbL loading of AgNPs onto nanocomplexes (Figure 1a). TMC is a positively charged polysaccharide (Figure 1d), which is biocompatible and has mucoadhesive properties, making it particularly attractive for applications in both oral and pulmonary drug delivery. ${ }^{47-49}$ Additionally, TMC has been used in combination with DS to form nanocomplexes for use in drug delivery applications. ${ }^{48}$ TMC was first incubated with AgNPs at a mass ratio of $1: 1$ to initiate complexation and form positively charged AgNPs. An immediate color change was observed upon co-incubation, indicating successful displacement of citrate coatings with TMC. TMC-coated AgNPs were then added to Tob-NCs to form AgTob-NCs and additional TMC was added to stabilize the particles and prevent aggregation. Using this method at $\mathrm{Na}$ acetate $\mathrm{pH} 4$, quantitative loading of AgNPs onto NCs was observed, with tunable mass ratios of Ag:Tob ranging from 1:2 to 1:8. A ratio of 1:2 Ag:Tob was chosen to maximize loading and subsequent synergistic antimicrobial activities. Interestingly, the immediate addition of AgNPs to freshly formed Tob-NCs led to a 50-100 nm decrease in particle diameter (Figure 2a,e). This phenomenon is likely due to the strong electrostatic attraction between TMC and DS, as has been observed previously. ${ }^{48}$ This strong complexation also led to an increase in overall Tob ee\% for AgTob-NCs, increasing from $58 \%$ for Tob-NC 1 c to $>75 \%$ encapsulation efficiencies for all AgTobNCs fabricated.

In addition to co-loading AgNPs and Tob onto a singular nanocarrier, we were interested in modulating the physicochemical properties of these NCs to design their biointerfacial interactions with bacterial biofilms. As Pseudomonas biofilms are composed of negatively charged biopolymers such as eDNA and alginate, we hypothesized that positively charged NCs of a 200$300 \mathrm{~nm}$ size regime could initiate interactive filtering within biofilms, ${ }^{8,42}$ with their size enabling steric diffusion through biofilm hydrogel pores while still allowing for electrostatic engagement with the biofilm matrix to increase NC attachment and antimicrobial delivery. To create positively charged AgTob-NCs, additional equivalents of TMC were added following AgNP co-incubation. These studies yielded two different NC formulations, AgTob-NC 2a bearing a negatively charged surface, and AgTob-NC $\mathbf{2 b}$ with a positively charged surface (Figure $\mathbf{2 a}, \mathbf{e}$ ). Both $\mathbf{2 a}$ and $\mathbf{2 b}$ had similar degrees of Tob ee\%, with $\mathbf{2} \mathbf{b}$ being of slight increased size, likely owing to the additional TMC layers coating its surface.

\subsection{Storage, Stability, and Biocompatibility of AgTob-NCs}

AgTob-NCs $\mathbf{2 a}$ and $\mathbf{2} \mathbf{b}$ were evaluated for their long-term storage potential, stability in biological environments, and biocompatibility. Both NC $\mathbf{2 a}$ and $\mathbf{2 b}$ were able to be lyophilized and resuspended without significant aggregation or destabilization, although a slight increase in particle size to $\sim 300 \mathrm{~nm}$ in diameter was observed upon resuspension (Figure S2). To determine whether the NCs would destabilize or aggregate in biological media, NCs were incubated in 10\% FBS for $20 \mathrm{~h}$ at $37{ }^{\circ} \mathrm{C}$ prior to characterization via DLS. NC $\mathbf{2 a}$ maintained its size and no 
aggregation was observed, while $\mathbf{2 b}$ increased in size to $\sim 1 \mu \mathrm{m}$ (Figure S2), likely owing to modest aggregation of NCs through the adsorption of serum proteins onto the positively charged particle surfaces. However, for both NCs no large aggregation was visible by eye, indicating sufficient bio-stability. Presto Blue cell viability studies were performed using A549 lung cells incubated with AgNPs or NCs for $24 \mathrm{~h}$. AgNPs can be cytotoxic at higher concentrations, ${ }^{50,51}$ however we observed only modest decreases in cell viability to $\sim 85 \%$ with AgNPs or NCs 2 a and $\mathbf{2 b}$ at the highest dosage tested of $4 \mu \mathrm{g}$ AgNP per 20,000 cells, with no significant differences measured between groups (Figure S3). Thus, AgTob-NCs demonstrated favorable properties for long-term storage, stability, and biocompatibility.

\subsection{Antimicrobial Activity of AgTob-NCs Against Planktonic $P$. aeruginosa}

With both NC formulations in hand, we set out to evaluate whether NC-mediated co-delivery of $\mathrm{Ag}$ and Tob provided improved antimicrobial activity against planktonic cultures of $P$. aeruginosa. Laboratory strain PA14 was used for all antimicrobial activity assays, as PA14 is a well-studied virulent PA strain and can be cultured to form robust biofilms. ${ }^{52-54}$ To evaluate the antimicrobial activities of NCs against planktonic PA14, tobramycin, AgNPs, and AgTob-NC 2a and $\mathbf{2 b}$ were cultured with dilute concentrations of PA for $20 \mathrm{~h}$ to determine the minimum inhibitory concentration (MIC) of tobramycin required to inhibit $80 \%$ of bacterial growth for each group relative to untreated PA14 cultures (Figure 3).

Tobramycin alone had an MIC value of $8 \mu \mathrm{g} / \mathrm{ml}$, which is in agreement with the range commonly reported in the literature for tobramycin bacteriostatic activity against PA. ${ }^{55,56}$ When coupled with AgNPs either co-incubated in solution (AgNP + Tob control) or co-loaded into NCs $\mathbf{2 a}$ and $\mathbf{2} \mathbf{b}$, a significant enhancement in antimicrobial activity was observed, with Tob MIC values decreasing to $2 \mu \mathrm{g} / \mathrm{ml}$ (Figure 3). AgNPs alone had an MIC value of $4 \mu \mathrm{g} / \mathrm{ml}$ (data not shown), leading to a fractional inhibitory concentration (FIC) index value of 0.5 , confirming synergistic activity as defined by $\mathrm{FIC} \leq 0.5 .^{57}$ No significant differences were observed between any of the Ag+Tob treatment groups. Thus, $\mathrm{NCs} \mathbf{2} \mathbf{a}$ and $\mathbf{2} \mathbf{b}$ were able to deliver both antimicrobials effectively without sacrificing drug potency and enhanced the inhibition of planktonic $P$. aeruginosa growth when compared to Tob or AgNP treatments alone.

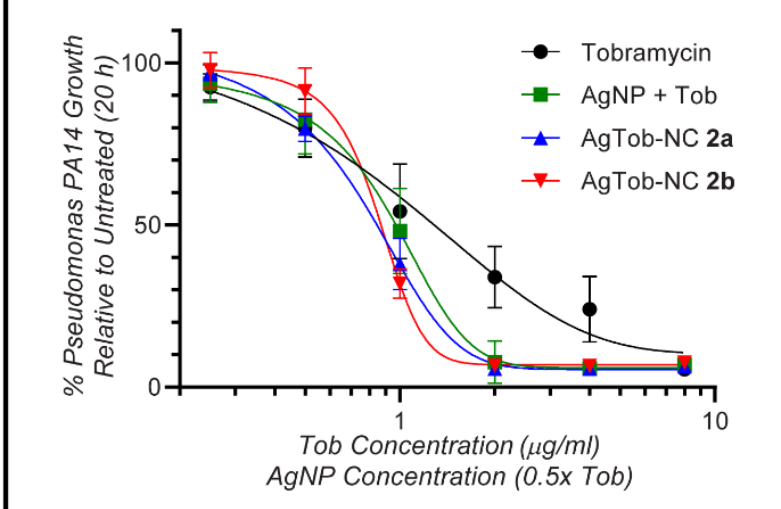

Figure 3. Antimicrobial activity of AgTob-NCs against planktonic Pseudomonas aeruginosa cultures. PA14 laboratory strains were incubated with Tob, AgNPs+Tob, or AgTob-NC formulations for $20 \mathrm{~h}$ while shaking, prior to measuring bacterial growth at OD600. The minimum inhibitory concentration (MIC 80 ) of tobramycin decreased from $8 \mu \mathrm{g} / \mathrm{ml}$ to $2 \mu \mathrm{g} / \mathrm{ml}$ with AgTob-NC treatment, demonstrating effective co-delivery and synergistic enhancement in antimicrobial activity.

\subsection{Antimicrobial Activities of AgTob-NCs Against $\boldsymbol{P}$. aeruginosa Biofilms}

As the majority of PA infections exist as biofilms and are associated with high rates of AMR, we next evaluated the antimicrobial activities of AgTob-NCs against PA14 biofilms. Biofilms were 
cultured using previously reported protocols ${ }^{54}$ for $24 \mathrm{~h}$ prior to the addition of therapeutics and further incubation for $20 \mathrm{~h}$. PA14 biofilms were stained using a BacLight live/dead bacterial stain, with Syto9 (S9) acting as a universal stain for all bacteria and propidium iodide (PI) as a dead stain for bacteria with permeable membranes. PA14 grew into robust biofilms that displayed significant antimicrobial resistance to tobramycin, even at higher dosages of $40 \mu \mathrm{g} / \mathrm{ml}$, corresponding to $6.4 \mathrm{\mu g}$ of Tob per well (Figure 4a). AgNP treatment alone also demonstrated no observable antimicrobial or antibiofilm activities (Figure S4). Interestingly, Tob and AgNP individual treatments led to greater biofilm formation than untreated biofilm controls (Figure S4), which agrees with literature reports of sublethal antimicrobial concentrations enhancing biofilm growth. ${ }^{58,59}$ While dead bacteria were observed with Tob treatment, PI-stained bacteria were predominantly found outside of biofilm morphologies, indicating that while Tob may be effective against planktonic PA14, it was unable to penetrate through the biofilm hydrogels to achieve effective antimicrobial activity, as has been previously observed in literature reports. $5,8,60$

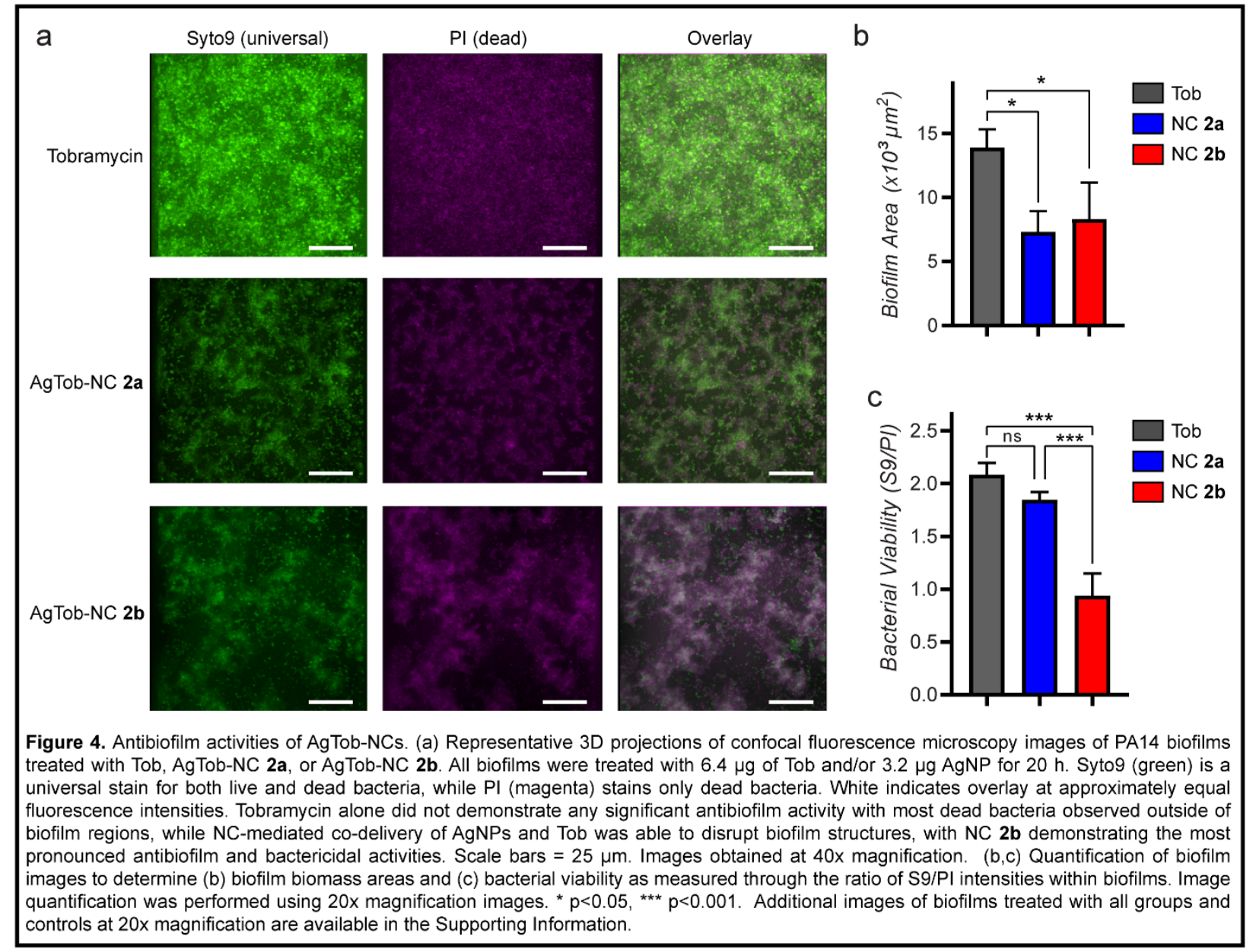

While neither tobramycin nor AgNP treatments alone could reduce biofilm formation or lead to significant reductions in bacterial viability, both AgTob-NCs $\mathbf{2 a}$ and $\mathbf{2 b}$ treatments led to observable disruptions in biofilm morphologies and significant reductions in bacterial biomass (Figure 4b). Images were quantified to determine the ratios of S9/PI fluorescence intensity as a marker for bacterial viability within biofilms. Only NC $\mathbf{2 b}$ led to a significant loss in bacterial viability within biofilms, with S9/PI ratios decreasing to $\sim 1.0$, indicating that all the bacteria present within 
the biofilms were dead (Figure 4c). As the predominant difference between NC formulations was in the increased TMC coating and positive charge of $\mathrm{NC} \mathbf{2 b}$, it is therefore likely that the increased interactions between the positively charged TMC on NC $\mathbf{2 b}$ and the bacterial biofilm matrix led to enhanced biofilm disruption and antimicrobial activities. These studies therefore demonstrate the importance of drug carrier biointerface design, as these considerations can have significant effects on delivery efficiencies and therapeutic outcomes.

\section{Conclusions}

Rising rates of antimicrobial resistant bacterial biofilm infections coupled with a near-halt in the approval of new antibiotics have led to a global crisis and fears of entering a post-antibiotic era. It is therefore imperative to develop new drug carrier formulations capable of enhancing the activities of already-approved antibiotics such as tobramycin and other aminoglycosides. By combining polyelectrolyte nanocomplexation with layer-by-layer electrostatic self-assembly, we developed a new class of nanoscale drug carrier, capable of co-delivering tobramycin antibiotics with antimicrobial silver nanoparticles. These NCs enabled Tob and AgNPs to work together to enhance antimicrobial activity against planktonic $P$. aeruginosa cultures and overcome antimicrobial resistant PA biofilms. By engineering the physicochemical properties of the nanocomplexes, we observed how properties such as surface chemistry influence resultant particle biointerfaces and lead to enhanced antimicrobial activity and biofilm disruption. Overall, this approach shows promise in the co-delivery of diverse classes of antimicrobials to treat bacterial infections, including the resistant biofilms found within chronic wounds and cystic fibrosis lung infections.

\section{Materials and Methods}

\subsection{General Methods and Instrumentation}

Unless otherwise noted, all reagents were purchased from commercial sources. Low molecular weight trimethyl chitosan was purchased from Sigma Aldrich (St. Louis, MO) with a reported $>70 \%$ degree of quaternization. $40 \mathrm{kDa}$ Dextran sulfate was purchased from Sigma Aldrich (St. Louis, $\mathrm{MO}$ ). All reagent solutions were freshly prepared for each experiment and fabrication process. Silver nanoparticles of $10 \mathrm{~nm}$ diameter were purchased from nanoComposix (San Diego, CA). Glycerol stocks of $P$. aeruginosa PA14 were generously provided by Dr. Oren Rosenberg. A549 lung cells were provided by the UCSF Cell and Genome Engineering Core.

Zeta potential and dynamic light scattering measurements were conducted on a Malvern Zetasizer Nano ZS. Absorbance and fluorescence quantification measurements were conducted on a Molecular Devices SpectraMax M5 plate reader. All fluorescence microscopy studies were conducted at the UCSF Nikon Imaging Center using a Nikon Ti spinning disk confocal microscope. Scanning Electron Microscopy (SEM) images were obtained at the UCSF Bioengineering \& Biomaterials Correlative Imaging Core using a Zeiss Sigma 500 VP (Carl Zeiss Microscopy $\mathrm{GmbH}$ ). 


\subsection{Tob-NC and AgTob-NC Fabrication}

Tobramycin and dextran sulfate (DS) were prepared as 20 and $40 \mathrm{mg} / \mathrm{mL}$ solutions in $\mathrm{ddH}_{2} \mathrm{O}$, respectively. NC formation was accomplished through stepwise addition of DS followed by Tob into a solution of $50 \mathrm{mM} \mathrm{Na}$ acetate $\mathrm{pH} 4$ for a final concentration of $2 \mathrm{mg} / \mathrm{mL}$ Tob and variable concentrations of DS to achieve mass ratios ranging from 1:1 to 1:4 Tob:DS. The solution was mixed by pipetting and left to incubate for at least 5 min before any subsequent reactions or characterizations.

For all AgTob-NC formulations, Tob-NCs were first fabricated at a 1:3 Tob:DS mass ratio. AgTob-NCs were typically fabricated at a $300 \mu \mathrm{L}$ scale. Prior to fabrication, TMC $(7.5 \mu \mathrm{L}$ of 4 $\mathrm{mg} / \mathrm{mL}$ in $\mathrm{Na}$ acetate $\mathrm{pH} 4$ ) and AgNPs (30 $\mu \mathrm{L}$ of $1 \mathrm{mg} / \mathrm{mL}$ stock solution obtained from commercial sources) were incubated together to achieve a 1:1 mass ratio. Next, a $75 \mu \mathrm{L}$ solution of $0.05 \%(w / v)$ tween was prepared in $\mathrm{ddH}_{2} \mathrm{O}$, to which were added Tob-NCs $(30 \mu \mathrm{L}, 2 \mathrm{mg} / \mathrm{mL})$, followed by the TMC-AgNP solution $(37.5 \mu \mathrm{L})$. Additional TMC was then added as a $45 \mu \mathrm{L}$ solution in $\mathrm{ddH}_{2} \mathrm{O}$ (1 equiv for NC 2a, 3.5 equiv for $\mathrm{NC} 2 \mathrm{~b}$ ), followed by $60 \mu \mathrm{L}$ of $5 \%(\mathrm{v} / \mathrm{v}$ ) of poly(vinyl alcohol) and $52.5 \mu \mathrm{L} d \mathrm{dH}_{2} \mathrm{O}$ to obtain AgTob-NCs as a $300 \mu \mathrm{L}$ solution at Tob and $\mathrm{Ag}$ concentrations of $200 \mu \mathrm{g} / \mathrm{mL}$ and $100 \mu \mathrm{g} / \mathrm{mL}$, respectively. Tween was used to prevent NC aggregation, while PVA was incorporated to enable the lyophilization of NCs for long-term storage. AgTob-NCs were either used immediately or flash-frozen and lyophilized.

\subsection{NC Characterization}

Dynamic light scattering (DLS) and zeta potential measurements were conducted using a Malvern Zetasizer Nano ZS. NCs were typically analyzed at a Tob concentration of $50-100 \mu \mathrm{g} / \mathrm{mL}$. Particle hydrodynamic diameters $\left(D_{h}\right)$ were reported using $Z_{\text {avg }}$ measurements. Full DLS curves were obtained for intensity size distributions (Figure S2). Encapsulation efficiencies (ee\%) for Tob were determined by analyzing the NC supernatants following centrifugation (13,000 rpm for $5 \mathrm{~min}$ ) to evaluate drug depletion after NC formation and LbL AgNP loading. Centrifugation at this speed and time allowed for the formation of an NC pellet without pelleting AgNPs or Tob. AgNP depletion was analyzed via UV-Vis absorbance at $390 \mathrm{~nm}$, while Tob depletion was assessed via an o-phthalaldehyde fluorescence assay. ${ }^{41}$ Briefly, o-phathalaldehyde was prepared as a 1 $\mathrm{mg} / \mathrm{mL}$ solution in $100 \mathrm{mM} \mathrm{Na}$ borate $\mathrm{pH} 10.4$ buffer with the addition of $\mathrm{MeOH}$ for $10 \%(\mathrm{v} / \mathrm{v})$ and $\beta$-mercaptoethanol for $0.5 \%(\mathrm{v} / \mathrm{v})$ final. o-Phthalaldehyde solutions $(15 \mu \mathrm{L})$ were added to $\mathrm{iPOH}$ $(90 \mu \mathrm{L})$ prior to the addition of sample supernatant $(15 \mu \mathrm{L})$. Solutions were incubated for $20 \mathrm{~min}$ and then analyzed for fluorescence intensity (360/450 ex/em) and compared to Tob calibration curves. o-Phthalaldehyde stock solutions could be stored at $4{ }^{\circ} \mathrm{C}$ for $1-2$ weeks without any observable loss in signal.

The morphology of the NC suspensions was determined using field emission scanning electron microscope (FE SEM), Zeiss Sigma 500 VP (Carl Zeiss Microscopy GmbH). Samples for electron microscopy were prepared by mounting droplets of NC suspensions (20 $\mu \mathrm{L})$ onto carbon substrate-coated SEM stubs and allowed to air dry. Subsequently, samples were stained with Uranyless. The Uranyless droplet was placed on the hydrophobic surface (parafilm). The stubs with NCs' side were placed on the Uranyless drop for 2 minutes and thereafter blotted by filter paper to remove access stain on the NCs. Followed by washing 3 times with $\mathrm{ddH}_{2} \mathrm{O}$ at room 
temperature. Finally, the samples were dried at room temperature for at least $12 \mathrm{~h}$ prior to analyze via FE SEM.

\subsection{Mammalian Cell Culture and Biocompatibility Studies}

A549 cells were cultured in F12 growth medium containing L-glutamine, supplemented with $10 \%$ fetal bovine serum and penicillin/streptomycin, and incubated at $37{ }^{\circ} \mathrm{C}$ and $5 \% \mathrm{CO}_{2}$. For biocompatibility studies, A549 cells were trypsinized, resuspended to a concentration of 100,000 cells $/ \mathrm{mL}$, and plated in triplicate into a 96 well plate for a final cell number of 10,000 cells/well. After $24 \mathrm{~h}$ incubation, the media was removed and replaced with $200 \mu \mathrm{L}$ of media + treatment (AgNP, AgTob-NC 2a, or AgTob-NC 2b). Treatments were prepared by fabricating the nanocomplexes as previously described at concentrations of $200 \mu \mathrm{g} / \mathrm{mL}$ Tob and $100 \mu \mathrm{g} / \mathrm{mL} \mathrm{Ag}$ in a final volume of $300 \mu \mathrm{L}$. This was further diluted into A549 media for a final Ag concentration of $20 \mu \mathrm{g} / \mathrm{mL}$, the highest concentration experimental condition. This was serially diluted $1: 2$ in A549 media until reaching $0.625 \mu \mathrm{g} \mathrm{Ag} / \mathrm{mL}$ and added to the cells. The cells were then incubated for an additional $24 \mathrm{~h}$. Following incubation, $20 \mu \mathrm{L}$ of Presto Blue were added to each well. The cells were then incubated for $1 \mathrm{~h}$ and Presto Blue fluorescence intensity (ex/em 560/590) was measured to determine cell viabilities relative to untreated cells.

\subsection{Planktonic $P$. aeruginosa Antimicrobial Activity Studies}

PA14 was cultured overnight from frozen glycerol stocks at $37^{\circ} \mathrm{C}$ and $220 \mathrm{rpm}$ in $\mathrm{LB}$ media. PA14 cultures were then refreshed by performing a 1:8 dilution into LB and shaken for an additional $1-3 \mathrm{~h}$ until an $\mathrm{OD}_{600}>0.4$ was achieved to confirm log-phase bacterial growth. PA14 was then plated into 96-well plates at $100 \mu \mathrm{L}$ and $\mathrm{OD}_{600}=0.002$ in accordance with previously reported methods. ${ }^{61}$ Next, $100 \mu \mathrm{L}$ of treatment groups and controls were added per well at $2 \mathrm{x}$ concentration to achieve PA14 $\mathrm{OD}_{600}=0.001$ and treatment concentrations starting at $8 \mu \mathrm{g} / \mathrm{mL}$ Tob and $4 \mu \mathrm{g} / \mathrm{mL}$ Ag with 1:2 serial dilutions to a final Tob concentration of $0.25 \mu \mathrm{g} / \mathrm{mL}$. All antimicrobial studies were performed with a minimum of $n=3$ biological replicates. Plates were then incubated at $37^{\circ} \mathrm{C}$ and $220 \mathrm{rpm}$ for $20 \mathrm{~h}$ prior to measurement of $O D_{600}$ to assess bacterial viability relative to untreated controls. MIC values are defined as the minimum concentration of drug required to inhibit $80 \%$ bacterial growth relative to untreated controls.

\section{6. $P$. aeruginosa Biofilm Studies}

PA14 biofilms were grown using previously reported methods. ${ }^{54}$ PA14 overnight cultures were refreshed by performing a 1:8 dilution into LB and shaken for an additional 1-3 $\mathrm{h}$ until an $\mathrm{OD}_{600}>$ 0.4 was achieved to confirm log-phase bacterial growth. Bacteria were then plated into half-area well plates (Greiner Bio-One) at $100 \mu \mathrm{L}$ and $\mathrm{OD}_{600}=0.02$ and sealed with air-permeable "BreatheEasy" membranes. Plates were then placed into a stationary incubator with water bath and incubated at $37{ }^{\circ} \mathrm{C}$ for $24 \mathrm{~h}$. After $24 \mathrm{~h}$, the air-permeable membranes were removed, and treatment groups were added to biofilms at $4 x$ concentrations and $40 \mu \mathrm{L}$ per well. Next, $20 \mu \mathrm{L}$ of BacLight dyes Syto9 and propidium iodide (co-incubated at 1:300 dilutions each from purchased stocks into PBS following manufacturer's instructions) were added to each well. Care was taken 
to add solutions dropwise to the top of each well without disturbing the biofilm. After treatment and BacLight dye addition, plates were sealed with air-permeable membranes and incubated at $37^{\circ} \mathrm{C}$ for $20 \mathrm{~h}$ with gentle rotations at $50 \mathrm{rpm}$. After $20 \mathrm{~h}$, bacterial biofilms were imaged using confocal fluorescence microscopy, with $\$ 9$ excited using a FITC channel and PI excited using a Cy3 channel. Images were acquired using both $20 x$ and $40 x$ air objectives. Images were acquired as Z-stacks of biofilms, with $2 \mu \mathrm{m}$ spacing and $50 \mu \mathrm{m}$ total slices. Z-stacks were centered at the z-position of highest S9 fluorescence intensity and relative z-stacks were obtained $\pm 25 \mu \mathrm{m}$ from that slice. All biofilm studies were performed with a minimum of $n=3$ biological replicates.

\subsection{P. aeruginosa Biofilm Image Analysis and Quantification}

Image quantification of biofilm area and viability was done through ImageJ. First, the background was subtracted from all images within a stack, based upon the z-slice that had the brightest S9 signal. A universal threshold value was applied to all images within a z-stack in order to segment biofilm mass from planktonic bacteria. This threshold was calculated based on Otsu's binarization of the $\$ 9$ channel in the untreated control biofilm. Within each segmented area of biomass, the average fluorescence intensities of S9 and PI were measured. This process was repeated for the 5 z-slices above and below the brightest S9 z-slice in a stack. Biofilm area, S9 fluorescence intensity, and PI fluorescence intensity were averaged from these 11 slices for each biofilm z-stack. Image analysis was conducted on z-stacks from 3 biological replicates and plotted as mean \pm standard deviation. Statistical analysis was performed using one-way ANOVA with multiple comparisons (Tukey's method).

\section{Supporting Information}

Figures S1-S4. SEM of Tob-NCs, AgTob-NC stability studies, Biocompatibility studies, Biofilm images at 20x magnification.

\section{Acknowledgments}

J.A.F. was supported by the UCSF HIVE postdoctoral fellowship. P.R. was supported by the National Science Foundation Graduate Research Fellowship and the NIH T32 Training Grant Program. M.A.Y. acknowledges support from the CFF LeRoy Matthews Award YU18L0. The authors acknowledge funding by the Cystic Fibrosis Foundation (Research Award \#835526).

\section{References}

(1) Dadgostar, P. Antimicrobial Resistance: Implications and Costs. Infect. Drug Resist. 2019, 12, 3903. https://doi.org/10.2147/IDR.S234610.

(2) Flemming, H.-C.; Wingender, J.; Szewzyk, U.; Steinberg, P.; Rice, S. A.; Kjelleberg, S. 
(3)

Biofilms: An Emergent Form of Bacterial Life. Nat. Rev. Microbiol. 2016, 14 (9), 563-575. https://doi.org/10.1038/nrmicro.2016.94.

Alav, I.; Sutton, J. M.; Rahman, K. M. Role of Bacterial Efflux Pumps in Biofilm Formation. J. Antimicrob. Chemother. 2018, 73 (8), 2003-2020. https://doi.org/10.1093/jac/dky042.

Van Acker, H.; Van Dijck, P.; Coenye, T. Molecular Mechanisms of Antimicrobial Tolerance and Resistance in Bacterial and Fungal Biofilms. Trends Microbiol. 2014, 22 (6), 326-333. https://doi.org/10.1016/j.tim.2014.02.001.

Tseng, B. S.; Zhang, W.; Harrison, J. J.; Quach, T. P.; Song, J. L.; Penterman, J.; Singh, P. K.; Chopp, D. L.; Packman, A. I.; Parsek, M. R. The Extracellular Matrix Protects Pseudomonas Aeruginosa Biofilms by Limiting the Penetration of Tobramycin. Environ. Microbiol. 2013, 15 (10), 2865-2878. https://doi.org/10.1111/1462-2920.12155.

d'Angelo, I.; Conte, C.; La Rotonda, M. I.; Miro, A.; Quaglia, F. Improving the Efficacy of Inhaled Drugs in Cystic Fibrosis: Challenges and Emerging Drug Delivery Strategies. Adv. Drug Deliv. Rev. 2014, 75, 92-111. https://doi.org/10.1016/J.ADDR.2014.05.008.

Ciofu, O.; Tolker-Nielsen, T.; Jensen, P. Ø.; Wang, H.; Høiby, N. Antimicrobial Resistance, Respiratory Tract Infections and Role of Biofilms in Lung Infections in Cystic Fibrosis Patients. Adv. Drug Deliv. Rev. 2015, 85, 7-23. https://doi.org/10.1016/j.addr.2014.11.017. Finbloom, J. A.; Sousa, F.; Stevens, M. M.; Desai, T. A. Engineering the Drug Carrier Biointerface to Overcome Biological Barriers to Drug Delivery. Adv. Drug Deliv. Rev. 2020. https://doi.org/10.1016/j.addr.2020.06.007.

Facchini, M.; De Fino, I.; Riva, C.; Bragonzi, A. Long Term Chronic Pseudomonas Aeruginosa Airway Infection in Mice. J. Vis. Exp. 2014, No. 85. https://doi.org/10.3791/51019.

Ramage, G.; Culshaw, S.; Jones, B.; Williams, C. Are We Any Closer to Beating the Biofilm: Novel Methods of Biofilm Control. Curr. Opin. Infect. Dis. 2010, 23 (6), 560-566. https://doi.org/10.1097/QCO.0b013e32833e5850.

Pang, Z.; Raudonis, R.; Glick, B. R.; Lin, T. J.; Cheng, Z. Antibiotic Resistance in Pseudomonas Aeruginosa: Mechanisms and Alternative Therapeutic Strategies. Biotechnol. Adv. 2019, 37 (1), 177-192. https://doi.org/10.1016/j.biotechadv.2018.11.013. Wu, H.; Moser, C.; Wang, H. Z.; Høiby, N.; Song, Z. J. Strategies for Combating Bacterial Biofilm Infections. Int. J. Oral Sci. $2014 \quad 71 \quad 2014, \quad 7 \quad$ (1), 1-7. https://doi.org/10.1038/ijos.2014.65.

Antoniu, S. Novel Inhaled Combined Antibiotic Formulations in the Treatment of Pseudomonas Aeruginosa Airways Infections in Cystic Fibrosis. Expert Rev. Anti-infective Ther. 2015, 13 (7), 897-905. https://doi.org/10.1586/14787210.2015.1041925.

Gupta, A.; Saleh, N. M.; Das, R.; Landis, R. F.; Bigdeli, A.; Motamedchaboki, K.; Campos, A. R.; Pomeroy, K.; Mahmoudi, M.; Rotello, V. M. Synergistic Antimicrobial Therapy Using Nanoparticles and Antibiotics for the Treatment of Multidrug-Resistant Bacterial Infection. Nano Futur. 2017, 1 (1). https://doi.org/10.1088/2399-1984/aa69fb.

Gupta, A.; Makabenta, J. M. V.; Schlüter, F.; Landis, R. F.; Das, R.; Cuppels, M.; Rotello, V. M. Functionalized Polymers Enhance Permeability of Antibiotics in Gram-Negative MDR Bacteria and Biofilms for Synergistic Antimicrobial Therapy. Adv. Ther. 2020, 3 (7), 2000005. https://doi.org/10.1002/adtp.202000005.

Habash, M. B.; Goodyear, M. C.; Park, A. J.; Surette, M. D.; Vis, E. C.; Harris, R. J.; Khursigara, C. M. Potentiation of Tobramycin by Silver Nanoparticles against Pseudomonas Aeruginosa Biofilms. Antimicrob. Agents Chemother. 2017, 61 (11). https://doi.org/10.1128/AAC.00415-17.

Kim, J.; Pitts, B.; Stewart, P. S.; Camper, A.; Yoon, J. Comparison of the Antimicrobial Effects of Chlorine, Silver Ion, and Tobramycin on Biofilm. Antimicrob. Agents Chemother. 2008, 52 (4), 1446-1453. https://doi.org/10.1128/AAC.00054-07.

Rai, M. K.; Deshmukh, S. D.; Ingle, A. P.; Gade, A. K. Silver Nanoparticles: The Powerful 
(19) Guo, Q.; Lan, T.; Chen, Y.; Xu, Y.; Peng, J.; Tao, L.; Shen, X. Enhanced of Antibacterial Activity of Antibiotic-Functionalized Silver Nanocomposites with Good Biocompatibility. J. Mater. Sci. Mater. Med. 2019, 30 (3). https://doi.org/10.1007/s10856-019-6236-8.

(20) Hatzenbuehler, J.; Pulling, T. J. Diagnosis and Management of Osteomyelitis. Am. Fam. Physician 2011, 84 (9), 1027-1033.

(21) Deusenbery, C.; Wang, Y.; Shukla, A. Recent Innovations in Bacterial Infection Detection and Treatment. ACS Infect. Dis. 2021, 7 (4), 695-720. https://doi.org/10.1021/ACSINFECDIS.0C00890.

(22) Chatterjee, M.; Anju, C. P.; Biswas, L.; Anil Kumar, V.; Gopi Mohan, C.; Biswas, R. Antibiotic Resistance in Pseudomonas Aeruginosa and Alternative Therapeutic Options. Int. J. Med. Microbiol. 2016, 306 (1), 48-58. https://doi.org/10.1016/j.jjmm.2015.11.004.

(23) Zhu, X.; Radovic-Moreno, A. F.; Wu, J.; Langer, R.; Shi, J. Nanomedicine in the Management of Microbial Infection - Overview and Perspectives. Nano Today 2014, 9 (4), 479-498. https://doi.org/10.1016/j.nantod.2014.06.003.

(24) Huh, A. J.; Kwon, Y. J. "Nanoantibiotics": A New Paradigm for Treating Infectious Diseases Using Nanomaterials in the Antibiotics Resistant Era. J. Control. Release 2011, 156 (2), 128-145. https://doi.org/10.1016/j.jconrel.2011.07.002.

(25) Uskoković, V.; Batarni, S. S.; Schweicher, J.; King, A.; Desai, T. A. Effect of Calcium Phosphate Particle Shape and Size on Their Antibacterial and Osteogenic Activity in the Delivery of Antibiotics in Vitro. ACS Appl. Mater. Interfaces 2013, 5 (7), 2422-2431. https://doi.org/10.1021/am4000694.

(26) Baptista, P. V.; McCusker, M. P.; Carvalho, A.; Ferreira, D. A.; Mohan, N. M.; Martins, M.; Fernandes, A. R. Nano-Strategies to Fight Multidrug Resistant Bacteria-"A Battle of the Titans". Front. Microbiol. 2018, 9 (JUL), 1-26. https://doi.org/10.3389/fmicb.2018.01441.

(27) Gupta, A.; Mumtaz, S.; Li, C. H.; Hussain, I.; Rotello, V. M. Combatting Antibiotic-Resistant Bacteria Using Nanomaterials. Chem. Soc. Rev. 2019, 48 (2), 415-427. https://doi.org/10.1039/c7cs00748e.

(28) Makabenta, J. M. V.; Nabawy, A.; Li, C. H.; Schmidt-Malan, S.; Patel, R.; Rotello, V. M. Nanomaterial-Based Therapeutics for Antibiotic-Resistant Bacterial Infections. Nat. Rev. Microbiol. 2021, 19 (1), 23-36. https://doi.org/10.1038/s41579-020-0420-1.

(29) d'Angelo, I.; Casciaro, B.; Miro, A.; Quaglia, F.; Mangoni, M. L.; Ungaro, F. Overcoming Barriers in Pseudomonas Aeruginosa Lung Infections: Engineered Nanoparticles for Local Delivery of a Cationic Antimicrobial Peptide. Colloids Surfaces B Biointerfaces 2015, 135, 717-725. https://doi.org/10.1016/j.colsurfb.2015.08.027.

(30) Kalelkar, P. P.; Riddick, M.; García, A. J. Biomaterial-Based Antimicrobial Therapies for the Treatment of Bacterial Infections. Nat. Rev. Mater. 2021. https://doi.org/10.1038/s41578-021-00362-4.

(31) Schneider, C. S.; Xu, Q.; Boylan, N. J.; Chisholm, J.; Tang, B. C.; Schuster, B. S.; Henning, A.; Ensign, L. M.; Lee, E.; Adstamongkonkul, P.; Simons, B. W.; Wang, S. Y. S.; Gong, X.; Yu, T.; Boyle, M. P.; Suk, J. S.; Hanes, J. Nanoparticles That Do Not Adhere to Mucus Provide Uniform and Long-Lasting Drug Delivery to Airways Following Inhalation. Sci. Adv. 2017, 3 (4). https://doi.org/10.1126/sciadv.1601556.

(32) Azarmi, S.; Roa, W. H.; Löbenberg, R. Targeted Delivery of Nanoparticles for the Treatment of Lung Diseases. Adv. Drug Deliv. Rev. 2008, 60 (8), 863-875. https://doi.org/10.1016/j.addr.2007.11.006.

(33) Yang, W.; Peters, J. I.; Williams, R. O. Inhaled Nanoparticles-A Current Review. Int. J. Pharm. 2008, 356 (1-2), 239-247. https://doi.org/10.1016/j.jpharm.2008.02.011.

(34) Haque, S.; Whittaker, M. R.; Mclntosh, M. P.; Pouton, C. W.; Kaminskas, L. M. Disposition and Safety of Inhaled Biodegradable Nanomedicines: Opportunities and Challenges. 
Nanomedicine Nanotechnology, Biol. Med. 2016, 12 (6), 1703-1724. https://doi.org/10.1016/j.nano.2016.03.002.

(35) Kinnear, C.; Moore, T. L.; Rodriguez-Lorenzo, L.; Rothen-Rutishauser, B.; Petri-Fink, A. Form Follows Function: Nanoparticle Shape and Its Implications for Nanomedicine. Chem. Rev. 2017, 117 (17), 11476-11521. https://doi.org/10.1021/acs.chemrev.7b00194.

(36) Zhao, Z.; Ukidve, A.; Krishnan, V.; Mitragotri, S. Effect of Physicochemical and Surface Properties on in Vivo Fate of Drug Nanocarriers. Adv. Drug Deliv. Rev. 2019, 143, 3-21. https://doi.org/10.1016/j.addr.2019.01.002.

(37) Marras, A. E.; Ting, J. M.; Stevens, K. C.; Tirrell, M. V. Advances in the Structural Design of Polyelectrolyte Complex Micelles. J. Phys. Chem. B 2021, 125 (26), 7076-7089. https://doi.org/10.1021/ACS.JPCB.1C01258.

(38) Wu, D.; Zhu, L.; Li, Y.; Zhang, X.; Xu, S.; Yang, G.; Delair, T. Chitosan-Based Colloidal Polyelectrolyte Complexes for Drug Delivery: A Review. Carbohydr. Polym. 2020, 238 (December 2019). https://doi.org/10.1016/j.carbpol.2020.116126.

(39) Kulkarni, A. D.; Vanjari, Y. H.; Sancheti, K. H.; Patel, H. M.; Belgamwar, V. S.; Surana, S. J.; Pardeshi, C. V. Polyelectrolyte Complexes: Mechanisms, Critical Experimental Aspects, and Applications. Artif. Cells, Nanomedicine Biotechnol. 2016, 44 (7), 1615-1625. https://doi.org/10.3109/21691401.2015.1129624.

(40) Porsio, B.; Cusimano, M. G.; Schillaci, D.; Craparo, E. F.; Giammona, G.; Cavallaro, G. Nano into Micro Formulations of Tobramycin for the Treatment of Pseudomonas Aeruginosa Infections in Cystic Fibrosis. Biomacromolecules 2017, 18 (12), 3924-3935. https://doi.org/10.1021/acs.biomac.7b00945.

(41) Hill, M.; Cunningham, R. N.; Hathout, R. M.; Johnston, C.; Hardy, J. G.; Migaud, M. E. Formulation of Antimicrobial Tobramycin Loaded PLGA Nanoparticles via Complexation with AOT. J. Funct. Biomater. 2019, 10 (2). https://doi.org/10.3390/JFB10020026.

(42) Witten, J.; Ribbeck, K. The Particle in the Spider's Web: Transport through Biological Hydrogels. Nanoscale 2017, 9 (24), 8080-8095. https://doi.org/10.1039/c6nr09736g.

(43) Correa, S.; Dreaden, E. C.; Gu, L.; Hammond, P. T. Engineering Nanolayered Particles for Modular Drug Delivery. J. Control. Release 2016, 240, 364-386. https://doi.org/10.1016/j.jconrel.2016.01.040.

(44) Alkekhia, D.; Hammond, P. T.; Shukla, A. Layer-by-Layer Biomaterials for Drug Delivery. Annu. Rev. Biomed. Eng. 2020, 22, 1-24. https://doi.org/10.1146/annurev-bioeng-060418052350.

(45) Alkekhia, D.; Shukla, A. Influence of Poly-l-Lysine Molecular Weight on Antibacterial Efficacy in Polymer Multilayer Films. J. Biomed. Mater. Res. Part A 2019, 107 (6), 13241339. https://doi.org/10.1002/JBM.A.36645.

(46) Finbloom, J. A.; Demaree, B.; Abate, A. R.; Desai, T. A. Networks of High Aspect Ratio Particles to Direct Colloidal Assembly Dynamics and Cellular Interactions. Adv. Funct. Mater. 2020. https://doi.org/10.1002/adfm.202005938.

(47) Ahadian, S.; Finbloom, J. A.; Mofidfar, M.; Diltemiz, S. E.; Nasrollahi, F.; Davoodi, E.; Hosseini, V.; Mylonaki, I.; Sangabathuni, S.; Montazerian, H.; Fetah, K.; Nasiri, R.; Dokmeci, M. R.; Stevens, M. M.; Desai, T. A.; Khademhosseini, A. Micro and Nanoscale Technologies in Oral Drug Delivery. Adv. Drug Deliv. Rev. 2020. https://doi.org/10.1016/j.addr.2020.07.012.

(48) Kulkarni, A. D.; Vanjari, Y. H.; Sancheti, K. H.; Patel, H. M.; Belgamwar, V. S.; Surana, S. J.; Pardeshi, C. V. New Nasal Nanocomplex Self-Assembled from Charged Biomacromolecules: N,N,N-Trimethyl Chitosan and Dextran Sulfate. Int. J. Biol. Macromol. 2016, 88, 476-490. https://doi.org/10.1016/j.ijbiomac.2016.03.045.

(49) Kulkarni, A. D.; Patel, H. M.; Surana, S. J.; Vanjari, Y. H.; Belgamwar, V. S.; Pardeshi, C. V. N,N,N-Trimethyl Chitosan: An Advanced Polymer with Myriad of Opportunities in Nanomedicine. Carbohydr. Polym. 2017, 157, 875-902. 
(50) Liao, C.; Li, Y.; Tjong, S. C. Bactericidal and Cytotoxic Properties of Silver Nanoparticles. Int. J. Mol. Sci. 2019, 20 (2). https://doi.org/10.3390/IJMS20020449.

(51) Zhang, T.; Wang, L.; Chen, Q.; Chen, C. Cytotoxic Potential of Silver Nanoparticles. Yonsei Med. J. 2014, 55 (2), 283. https://doi.org/10.3349/YMJ.2014.55.2.283.

(52) Qu, J.; Prasad, N. K.; Yu, M. A.; Chen, S.; Lyden, A.; Herrera, N.; Silvis, M. R.; Crawford, E.; Looney, M. R.; Peters, J. M.; Rosenberg, O. S. Modulating Pathogenesis with MOBILECRISPRI. J. Bacteriol. 2019, 201 (22). https://doi.org/10.1128/JB.0030419/FORMAT/EPUB.

(53) De Soyza, A.; Hall, A. J.; Mahenthiralingam, E.; Drevinek, P.; Kaca, W.; Drulis-Kawa, Z.; Stoitsova, S. R.; Toth, V.; Coenye, T.; Zlosnik, J. E. A.; Burns, J. L.; Sá-Correia, I.; De Vos, D.; Pirnay, J. P.; J. Kidd, T.; Reid, D.; Manos, J.; Klockgether, J.; Wiehlmann, L.; Tümmler, B.; Mcclean, S.; Winstanley, C. Developing an International Pseudomonas Aeruginosa Reference Panel. Microbiologyopen 2013, 2 (6), 1010-1023. https://doi.org/10.1002/mbo3.141.

(54) Müsken, M.; Di Fiore, S.; Römling, U.; Häussler, S. A 96-Well-Plate-Based Optical Method for the Quantitative and Qualitative Evaluation of Pseudomonas Aeruginosa Biofilm Formation and Its Application to Susceptibility Testing. Nat. Protoc. 2010, 5 (8), 14601469. https://doi.org/10.1038/nprot.2010.110.

(55) Shawar, R. M.; MacLeod, D. L.; Garber, R. L.; Burns, J. L.; Stapp, J. R.; Clausen, C. R.; Tanaka, S. K. Activities of Tobramycin and Six Other Antibiotics against Pseudomonas Aeruginosa Isolates from Patients with Cystic Fibrosis. Antimicrob. Agents Chemother. 1999, 43 (12), 2877-2880. https://doi.org/https://doi.org/10.1128/aac.43.12.2877.

(56) Ghorbani, H.; Memar, M. Y.; Sefidan, F. Y.; Yekani, M.; Ghotaslou, R. In Vitro Synergy of Antibiotic Combinations against Planktonic and Biofilm Pseudomonas Aeruginosa. GMS Hyg. Infect. Control 2017, 12, Doc17. https://doi.org/10.3205/dgkh000302.

(57) Doern, C. D. When Does 2 Plus 2 Equal 5? A Review of Antimicrobial Synergy Testing. J. Clin. Microbiol. 2014, 52 (12), 4124. https://doi.org/10.1128/JCM.01121-14.

(58) Hoffman, L. R.; D’Argenio, D. A.; MacCoss, M. J.; Zhang, Z.; Jones, R. A.; Miller, S. I. Aminoglycoside Antibiotics Induce Bacterial Biofilm Formation. Nature 2005, 436 (7054), 1171-1175. https://doi.org/10.1038/nature03912.

(59) Tahrioui, A.; Duchesne, R.; Bouffartigues, E.; Rodrigues, S.; Maillot, O.; Tortuel, D.; Hardouin, J.; Taupin, L.; Groleau, M. C.; Dufour, A.; Déziel, E.; Brenner-Weiss, G.; Feuilloley, M.; Orange, N.; Lesouhaitier, O.; Cornelis, P.; Chevalier, S. Extracellular DNA Release, Quorum Sensing, and PrrF1/F2 Small RNAs Are Key Players in Pseudomonas Aeruginosa Tobramycin-Enhanced Biofilm Formation. npj Biofilms Microbiomes 201951 2019, 5 (1), 1-11. https://doi.org/10.1038/s41522-019-0088-3.

(60) Sønderholm, M.; Kragh, K. N.; Koren, K.; Jakobsen, T. H.; Darch, S. E.; Alhede, M.; Jensen, P. Ø.; Whiteley, M.; Kühl, M.; Bjarnsholt, T. Pseudomonas Aeruginosa Aggregate Formation in an Alginate Bead Model System Exhibits In Vivo-Like Characteristics. Appl. Environ. Microbiol. 2017, 83 (9). https://doi.org/10.1128/AEM.00113-17.

(61) Agarwal, R.; Johnson, C. T.; Imhoff, B. R.; Donlan, R. M.; McCarty, N. A.; García, A. J. Inhaled Bacteriophage-Loaded Polymeric Microparticles Ameliorate Acute Lung Infections. Nat. Biomed. Eng. 2018, 2 (11), 841-849. https://doi.org/10.1038/s41551-018-0263-5. 